\title{
Influence of hot isostatic pressing on microstructure, properties and deformability of selective laser melting TC4 alloy
}

\author{
Tai-qi Yan', *Bing-qing Chen ${ }^{\mathbf{1}}$, Xia Ji ${ }^{\mathbf{2}}$, Shao-qing Guo' \\ 1. 3D Printing Research and Engineering Technology Center, Beijing Institute of Aeronautical Materials, Beijing 100095, China \\ 2. Falcon Fast Manufacturing Technology Co., Ltd., Wuxi 214145, Jiangsu, China
}

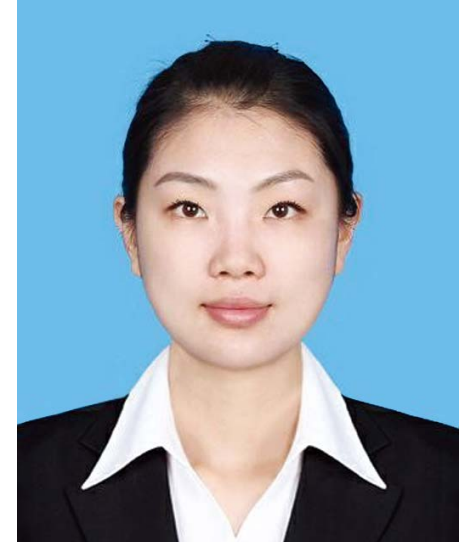

\section{*Bing-qing Chen}

Professor, Ph. D. Her research interests mainly focuse on additive manufacturing technology and welding technology of new aerospace material. She has participated in more than 20 projects, which financially supported by the National Natural Science Foundation of China, the Aeronautics Power Foundation, and the China-Netherlands Cooperation Project in Civil Aviation Science and Technology. So far, she has published more than $30 \mathrm{SCl}$ El academic papers and submitted applications for over 40 invention and defense patents of China. She was a winner of the "Youth Talent Promotion Project of China Association of Science and Technology" in 2016-2018.

E-mail: hwtkjcbq1984@163.com
Abstract: The influence of different hot isostatic pressing regimes on microstructure, phase constitution, microhardness, tensile properties and deformability of TC4 alloy fabricated by selective laser melting (SLM) technology was studied. The results show that the microstructure of SLM TC4 alloy is composed of acicular martensite $\alpha$ ' phase, and the sample exhibits high microhardness and strength, but low plasticity. After hot isostatic pressing, acicular martensite $\alpha^{\prime}$ phase transforms into $\alpha+\beta$ phase, and with the increase of hot isostatic pressing temperature and duration, $\alpha$ phase with coarse lath is gradually refined, and the proportion of $\alpha$ phase is gradually reduced. Because of the change of phase constitution in SLM TC4 alloy after hot isostatic pressing, the grain refinement strengthening is weakened, the density of dislocation is reduced, so that both microhardness and tensile strength are decreased by around $20 \%$, the elongation is increased by more than about $70 \%$, even over $100 \%$, compared with asdeposited TC4 alloy. When the hot isostatic pressing regime is $940{ }^{\circ} \mathrm{C} / 3 \mathrm{~h} / 150 \mathrm{MPa}$, the tensile strength and the elongation achieve optimal match, which are about $890 \mathrm{MPa}$ and around $14.0 \%$ in both directions. The fracture mechanism of alloy after $940{ }^{\circ} \mathrm{C} / 3 \mathrm{~h} / 150 \mathrm{MPa}$ HIP is dultile fracture. Hot isostatic pressing causes concave deformation of SLM TC4 alloy thin-walled frames, and the deformation degree increases with the increase of temperature.

Key words: selective laser melting; TC4 alloy; hot isostatic pressing; microstructure; mechanical properties; deformability

CLC numbers: TG146.23; Document code: A; Article ID: 1672-6421(2021)04-389-08

\section{Introduction}

TC4 alloy with the characteristics of light weight, high strength, good corrosion resistance and heat resistance is widely used in the aerospace field, and as an important engineering material for the manufacturing of aircraft parts ${ }^{[1,2]}$. At present, with the increasing demand for the integration and complexity of the aircraft parts, it is difficult to produce components with dimensional accuracy and acceptable surface quality by traditional processing technologies like casting and forging ${ }^{[3]}$. Selective laser melting (SLM) technology is particularly suitable for the preparation of the metal components with complicated structure ${ }^{[4-6]}$, which is decided by the unique technological process: using specific software to cut the three-dimensional (3D) model of the components to be processed into a series of layers with a certain thickness, then using a high-energy laser beam to melt metal powder selectively layer by layer according to each layer's data ${ }^{[7,8]}$. An attractive feature of this process is that there is no limit for the structural complexity of the parts, and it also has the advantages of high material utilization and no molds ${ }^{[9-11]}$.

However, SLM TC4 alloy usually retains high residual stress, and random distributed defects such as cracks and holes are easily formed inside, which may affect its mechanical 
properties ${ }^{[12]}$. In this case, the microstructure and properties are often regulated by heat treatment. Fan et al. ${ }^{[13]}$ found that after helding at $950{ }^{\circ} \mathrm{C}$ for $1 \mathrm{~h}$, part of $\alpha$ phase in SLM TC4 alloy was spheroidized, and other $\alpha$ phase still presented basket weave structure. Under this condition, the strength of the sample reached 1,200 MPa, but the elongation was only $2.42 \%$. Liang et al. ${ }^{[14]}$ studied the effects of 5 different heat treatment regimes on the microstructure and mechanical properties of SLM TC4 alloy. The results showed that, in maintaining heat treatment duration for $4 \mathrm{~h}$, with the increase of temperature from $650{ }^{\circ} \mathrm{C}$ to $900{ }^{\circ} \mathrm{C}$, $\alpha^{\prime}$ phase gradually decomposed into lamellar $\alpha+\beta$ structure, and almost completely decomposed at $800{ }^{\circ} \mathrm{C} / 4 \mathrm{~h}$, the elongation was more than $12 \%$, and the tensile strength was more than 1,000 MPa. Zhang et al. ${ }^{[15]}$ found that the microstructure changed from Widmanstatten to basket weave structure when the annealing temperature was above $800^{\circ} \mathrm{C}$. With the increase of annealing temperature, the tensile strength of the alloy decreased and the elongation increased. The SLM TC4 alloy subjected to heat treatment at $800{ }^{\circ} \mathrm{C} / 2 \mathrm{~h}$ had excellent comprehensive mechanical properties. It can be seen from the above research that heat treatment can reduce the residual stress of SLM TC4 alloy, and regulate the microstructure and properties. Hot isostatic pressing (HIP) can compact the internal defects through high pressure, thus improving the overall mechanical properties of the components. Xu et al. ${ }^{[16]}$ studied the effects of HIP temperature on as-cast TC4, the results showed that the shrinkage was reduced as the HIP temperature increased, and even completely closed above $920{ }^{\circ} \mathrm{C}$. Jiang et al. ${ }^{[17]}$ found that after HIP, the porosity defects in direct laser deposition Ti60 alloy disappeared, and the elongation increased from $6.5 \%$ to $12.0 \%$, while maintaining tensile strength over 1,000 MPa. Therefore, HIP may have more advantages in the post-processing of SLM components compared with annealing heat treatment in terms of eliminating the random hole defects that form in the SLM process ${ }^{[18]}$, thus improving the performance.

At present, the study on the effect of HIP on the microstructure and properties of SLM TC4 alloy is greatly insufficient. In this study, through the hot isostatic pressing method, the influence of temperature and duration of HIP on the microstructure, phase constitution, microhardness, tensile properties and deformability of SLM TC4 alloy was studied, which can provide theoretical basis and technical support for the manufacturing of aircraft parts.

\section{Experimental procedure}

The powder selected for the study was processed by highspeed plasma rotating electrode process. Table 1 shows the typical chemical composition of the TC4 powder. The TC4 powder morphology is shown in Fig. 1, showing that the surface of the powder particles is smooth and clean. The powder has high sphericity degree, up to $92.7 \%$. Powder particle size distribution is as follows: $D(10)=26.74 \mu \mathrm{m}$, $D(50)=40.41 \mu \mathrm{m}, D(90)=52.15 \mu \mathrm{m}$.

Table 1: Composition of experimental TC4 alloy powder (wt.\%)

\begin{tabular}{ccccccccccccccc} 
Ti & Al & Cu & Fe & Mn & Mo & Sn & V & C & H & N & O \\
\hline Balance & 6.02 & $<0.005$ & 0.062 & $<0.005$ & $<0.005$ & $<0.005$ & 4.02 & 0.0035 & 0.0042 & 0.038 & 0.096 \\
\hline
\end{tabular}

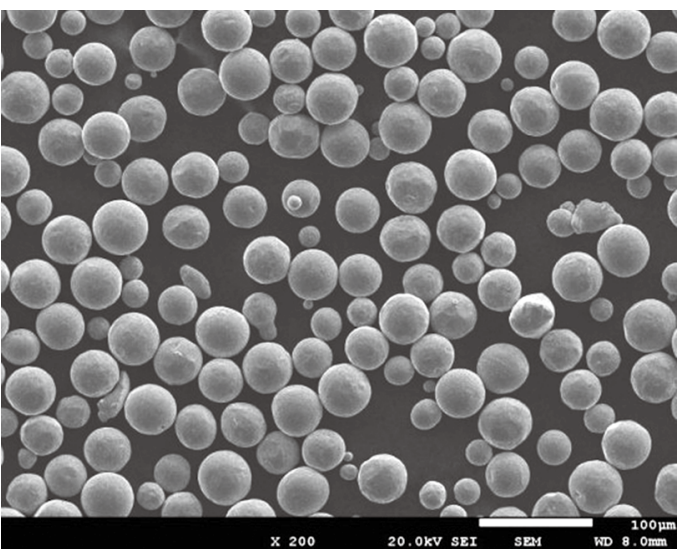

Fig. 1: Morphology of TC4 alloy powder
The SLM experiment was carried out with RenAM500 equipment produced by Renishaw Company, and the maximum forming volume of the equipment was $250 \mathrm{~mm} \times 250 \mathrm{~mm}$ $\times 350 \mathrm{~mm}$. Before SLM processing, the titanium alloy substrate was preheated to $170 \pm 2{ }^{\circ} \mathrm{C}$, and the forming chamber was filled with argon, to assure the oxygen content in the chamber was less than $0.05 \%$. The SLM processing parameters are shown in Table 2. A previous experiment showed that the TC4 alloy samples fabricated with these parameters had good formability, and the density of the samples was as high as $99.95 \%$. The frame samples with a length of $50 \mathrm{~mm}$, height of $20 \mathrm{~mm}$, and wall thickness of $1.5 \mathrm{~mm}$ were fabricated.

In order to find the difference in microstructure and mechanical properties of samples under different HIP regimes,

Table 2: SLM processing parameters

$\begin{array}{cccc}\text { Layer thickness }(\mathrm{mm}) & \text { Laser power }(\mathrm{W}) & \text { Scanning speed }\left(\mathrm{mm} \cdot \mathrm{s}^{-1}\right) & \text { Hatch spacing }(\mathrm{mm}) \\ 0.04 & 280 & 1,800 & 0.065\end{array}$


Table 3: HIP regimes of TC4 alloy

$\begin{array}{ccccc}\text { No. } & \text { Temperature }\left({ }^{\circ} \mathrm{C}\right) & \text { Time }(\mathrm{h}) & \text { Pressure (MPa) } & \text { Cooling mode } \\ 1 & 900 & 3 & 150 & \text { Furnace cooling } \\ 2 & 940 & 3 & & \\ 3 & 940 & 4 & \\ 4 & 960 & 4 & \end{array}$

four sets of HIP regimes were designed, as shown in Table 3. After grinding and polishing, the surfaces of the samples were etched by corrosion solution of $10 \% \mathrm{HNO}_{3}+5 \% \mathrm{HF}+85 \%$ $\mathrm{H}_{2} \mathrm{O}$ (in volume). The microstructure of the samples was observed by the Leica DM4000 metallographic microscope and FEI nano450 field emission scanning electron microscope (FESEM). The fracture morphology of SLM TC4 alloy after HIP of $940{ }^{\circ} \mathrm{C} / 3 \mathrm{~h} / 150 \mathrm{MPa}$ was also observed by FESEM. The phase analysis was carried out using D2 phaser X-ray diffraction (XRD). The microhardness was measured by HV-1000AT digital Vickers hardness tester, with $2 \mathrm{~N}$ load and $10 \mathrm{~s}$ loading time, and the hardness value was the average of 10 measurements. The tensile properties at room temperature were tested by AGIS250KN universal material testing machine with a tensile rate of $0.45 \mathrm{~mm} \cdot \mathrm{min}^{-1}$. An ATO three-dimensional optical scanner produced by German GOM company was employed to measure the deformation of the frames. Finally, through comparing the deformation of TC4 alloy frames before and after hot isostatic pressing, the influence of different hot isostatic pressing regimes on the specimen deformation was studied.

\section{Results and analysis}

\subsection{Effect of HIP on microstructure}

The microstructure of SLM TC4 alloy samples is shown

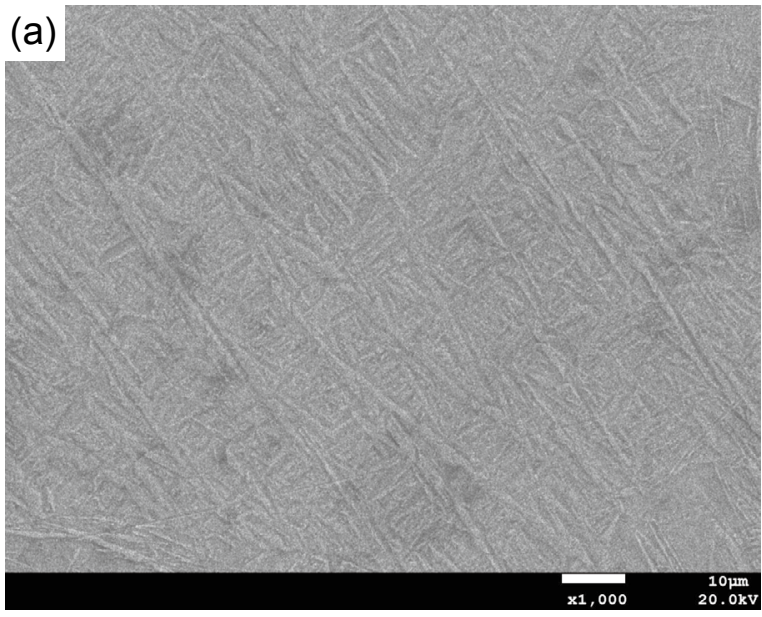

in Fig. 2. It can be seen that the morphology of the sample perpendicular to the building direction ( $X Y$ direction) is similar to that parallel to the building direction ( $Z$ direction): both directions achieve good metallurgical bonding, no cracks or lack of fusion defects are found, but there are few hole defects near $\beta$ grain boundary with a size about $1 \mu \mathrm{m}$ (Fig. 3), which may be related to the residual gas in the powder ${ }^{[19]}$. The microstructure is composed of fine needlelike phase interlaced with each other. According to TTT curve (isothermal transformation curve) of TC4 alloy ${ }^{[20]}$, different cooling rates can obtain different morphologies and types of microstructures. The cooling rate of cast TC4 alloy is only about $0.5^{\circ} \mathrm{C} \cdot \mathrm{s}^{-1}{ }^{[21]}$, the solidification process is so long that the grains have positive growth conditions to form thick strip-shaped $\alpha$ phase with certain orientations. However, the SLM process is a rapid heating and cooling process, and the cooling rate is as high as $10^{4}-10^{7} \mathrm{~K} \cdot \mathrm{s}^{-1}[22]$, so there is not enough time for the initially formed $\beta$ phase to transform into $\alpha$ phase, so it can only be transformed into martensite $\alpha$ phase by shear transformation ${ }^{[23]}$. Figure 4 shows the XRD diffraction pattern of SLM TC4 alloy, in which no $\beta$ phase diffraction peaks are found, but martensite $\alpha^{\prime}$ phase diffraction peaks with close-packed hexagonal structure are seen. The analysis above proves that the fine needle-like structure is martensite $\alpha^{\prime}$ phase.

Figure 5 shows the microstructure of SLM TC4 alloy after

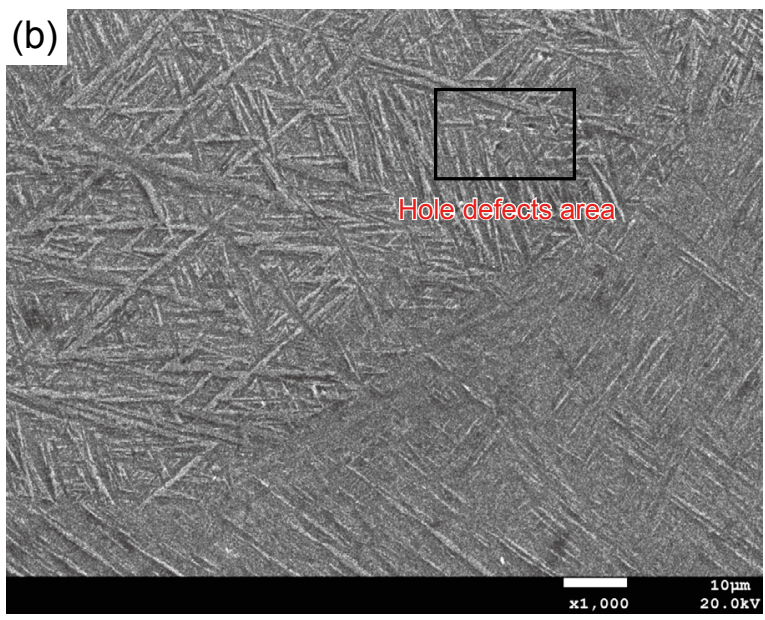

Fig. 2: Microstructure of SLM TC4 alloy: (a) XY direction; (b) Z direction 


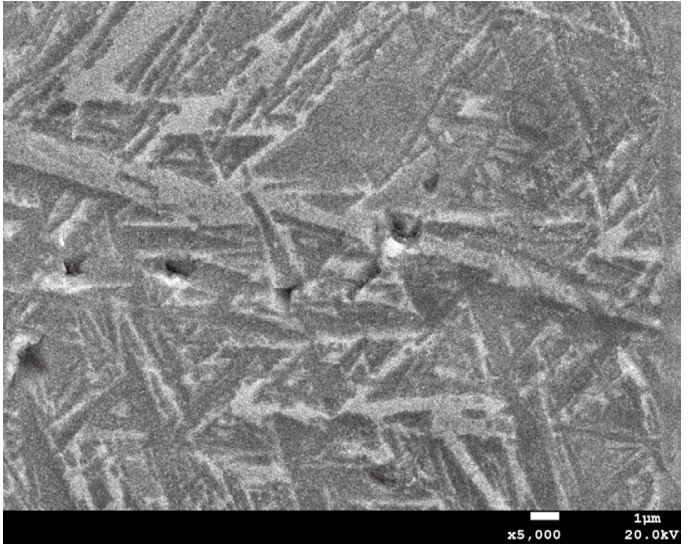

Fig. 3: Hole defects in SLM TC4 alloy

different HIP regimes. The results show that after HIP, hole defects that can be observed in SLM TC4 alloy are mostly closed, and the acicular martensite $\alpha^{\prime}$ phase disappears and transforms into $\alpha$ phase and $\beta$ phase. The microstructure in both directions is similar and there is no obvious difference. When the HIP regime is $900{ }^{\circ} \mathrm{C} / 3 \mathrm{~h} / 150 \mathrm{MPa}$, $\alpha$ phase appears to be coarse lath or even equiaxed. With the increase of HIP temperature and duration, the morphology of $\alpha$ phase with coarse lath is gradually refined, and the proportion of $\alpha$ phase is gradually reduced. Figure 6 shows the XRD diffraction patterns of SLM TC4 alloy under different HIP regimes. $\beta$ phase diffraction peak is still too weak to be observed, except a $\beta$ phase (110) peak (Fig. 6) under $940{ }^{\circ} \mathrm{C} / 3 \mathrm{~h} / 150 \mathrm{MPa}$. This is because in TC4 alloy, the
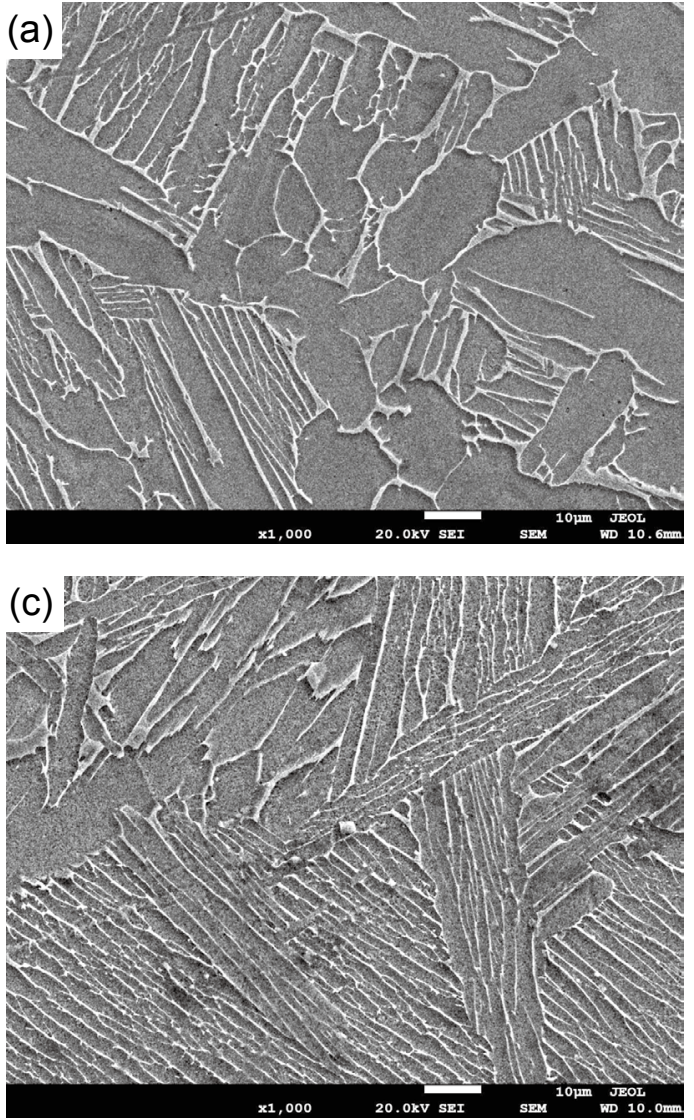

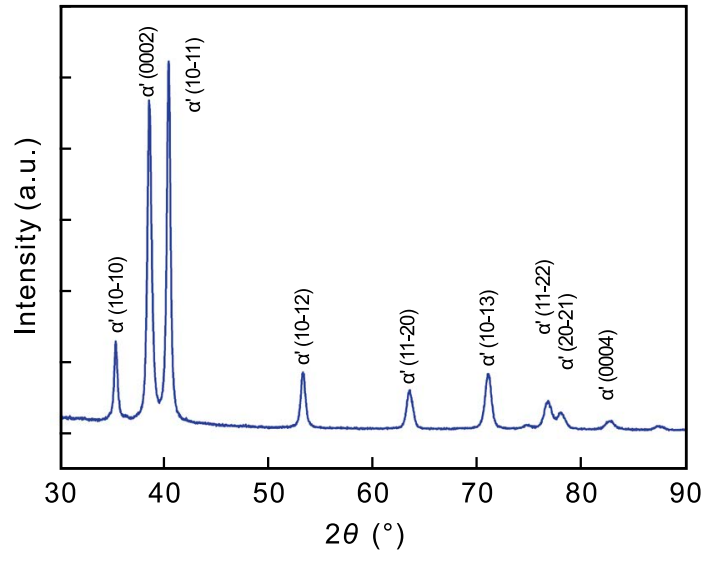

Fig. 4: XRD diffraction pattern of SLM TC4 alloy

content of $\alpha$ phase is dominant, the content of stable $\beta$ phase is very low, and $\beta$ phase is distributed in the grain boundaries of $\alpha$ phase in linear or dot shape, so it is difficult to observe the diffraction peak of $\beta$ phase in the XRD pattern of TC4 alloy. In addition, it can be seen that the diffraction peak intensity of $\alpha$ phase (10-11) in SLM TC4 alloy decreases gradually with the increase of temperature and duration of HIP, which may indicate the content of $\alpha$ phase decrease. This is consistent with the phenomenon observed in Fig. 5.

\subsection{Effect of HIP on microhardness}

Figure 7 shows the variation curves of microhardness of SLM TC4 alloy under different HIP temperatures and
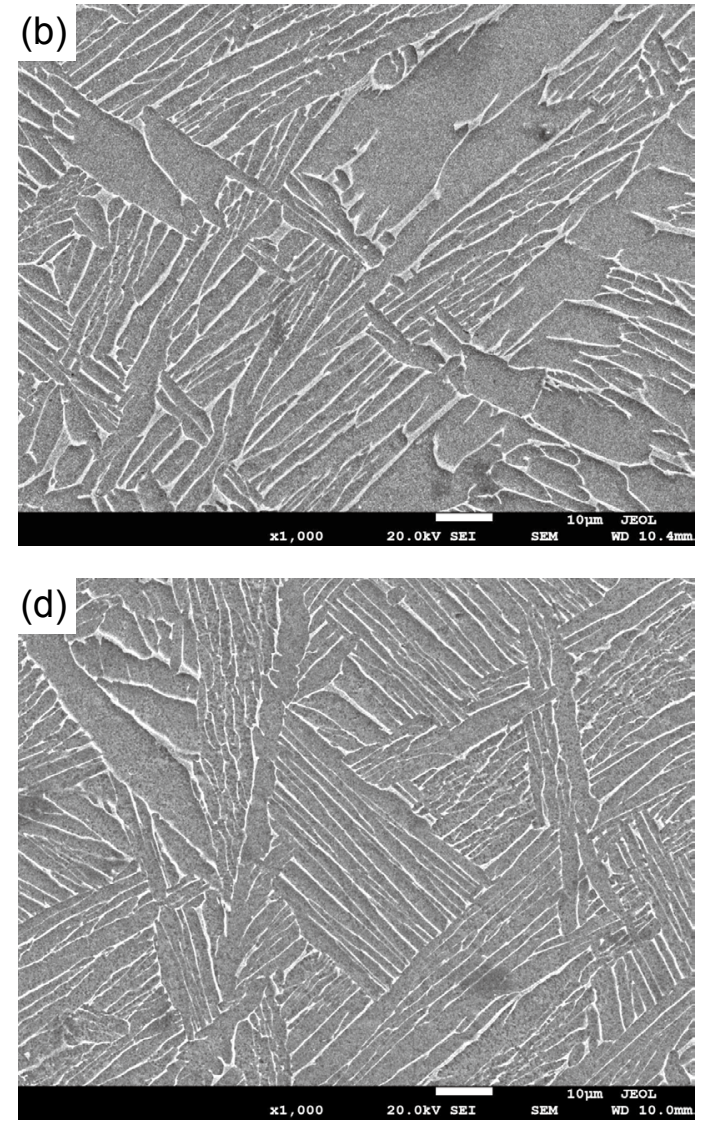

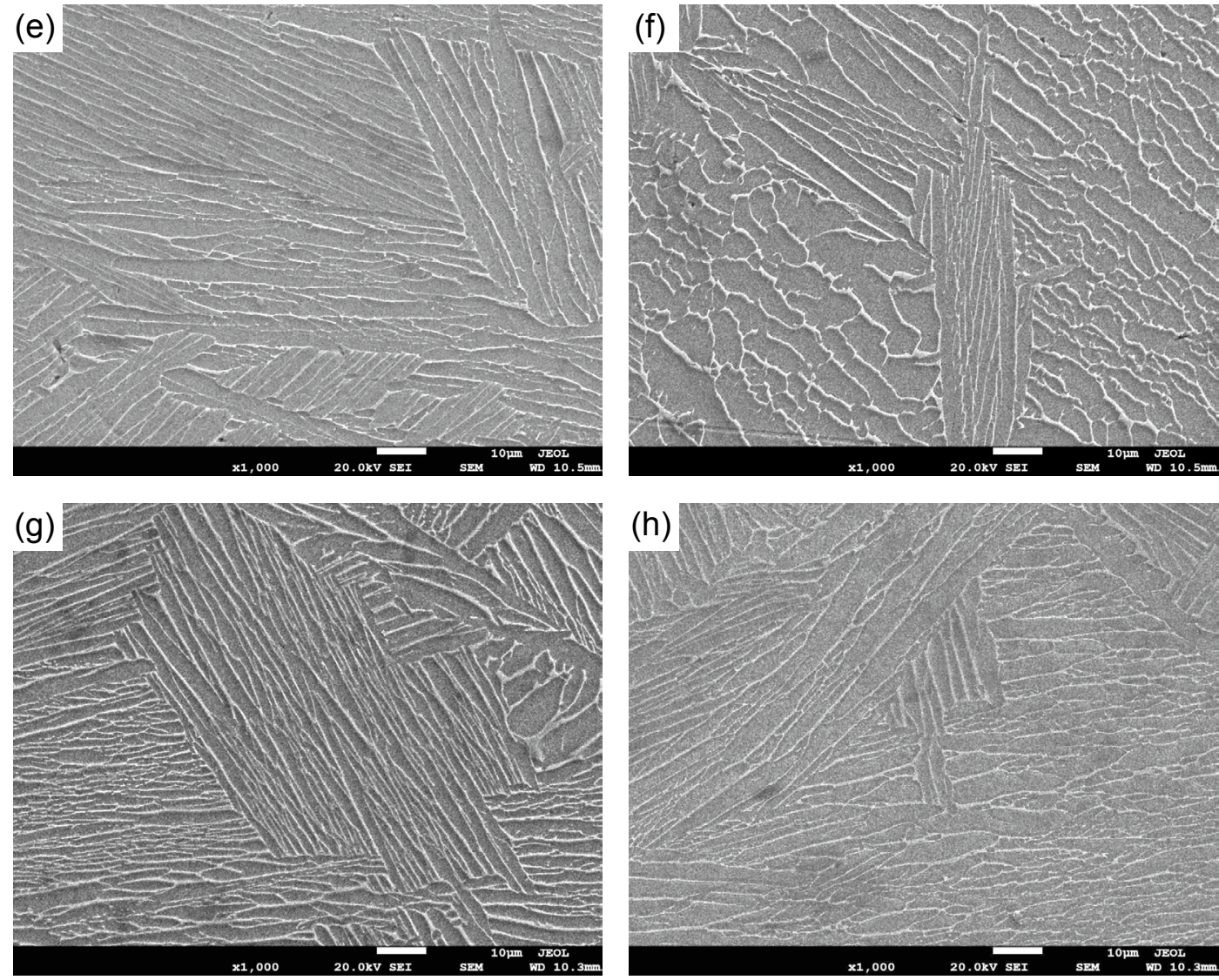

Fig. 5: Microstructures of SLM TC4 alloy under different HIP regimes: (a) $900{ }^{\circ} \mathrm{C} / 3 \mathrm{~h} / 150 \mathrm{MPa}, X Y$ direction; (b) $900{ }^{\circ} \mathrm{C} / 3 \mathrm{~h} / 150 \mathrm{MPa}, Z$ direction; (c) $940{ }^{\circ} \mathrm{C} / 3 \mathrm{~h} / 150 \mathrm{MPa}, X Y$ direction; (d) $940{ }^{\circ} \mathrm{C} / 3 \mathrm{~h} / 150 \mathrm{MPa}$, $Z$ direction; (e) $940^{\circ} \mathrm{C} / 4 \mathrm{~h} / 150 \mathrm{MPa}, X Y$ direction; (f) $940{ }^{\circ} \mathrm{C} / 4 \mathrm{~h} / 150 \mathrm{MPa}, Z$ direction; (g) $960^{\circ} \mathrm{C} / 4 \mathrm{~h} / 150 \mathrm{MPa}$, $X Y$ direction; (h) $960^{\circ} \mathrm{C} / 4 \mathrm{~h} / 150 \mathrm{MPa}, \mathrm{Z}$ direction

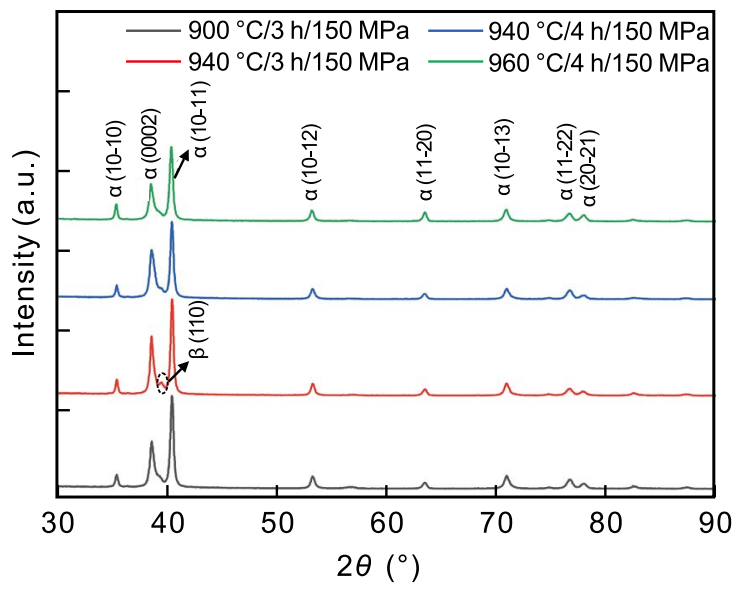

Fig. 6: XRD diffraction patterns of SLM TC4 alloy under different HIP regimes

duration. Because acicular martensite $\alpha^{\prime}$ phase is a sort of supersaturated solid solution, its microhardness is significantly higher than that of $\alpha$ phase. Therefore, the microhardness of SLM TC4 alloy is the highest, reaching more than $350 \mathrm{HV}$. After HIP, the microstructure is composed of $\alpha$ phase and $\beta$ phase, the microhardness decreases. With the increase of HIP temperature and duration, the microhardness decreases from around $320 \mathrm{HV}$ to $300 \mathrm{HV}$. On the one hand, HIP can effectively reduce the residual stress in the samples; on the other hand, the relative density of $\alpha$ phase is 0.74 with close packed hexagonal structure with 1 slip plane and 3 slip directions, while the relative density of $\beta$ phase is 0.68 with its body-centered cubic structure with 6 slip planes and 2 slip directions. Therefore, the plastic deformation ability of $\beta$ phase is stronger than that of $\alpha$ phase; that is to say, the higher the content of $\beta$ phase, the lower the microhardness of TC4 alloy ${ }^{[24]}$. According to the microstructure shown in Fig. 5, with the increase of HIP temperature and duration, the content of $\beta$ phase increases, so the microhardness gradually decreases.

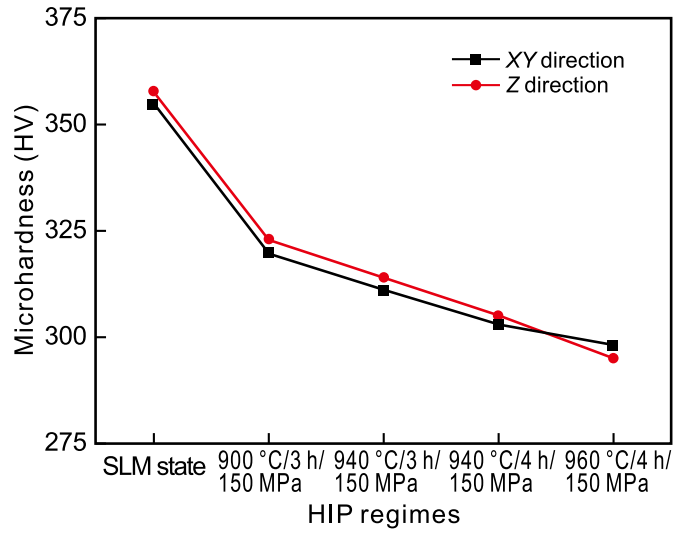

Fig. 7: Microhardness of SLM TC4 alloy under different HIP regimes 


\subsection{Effect of HIP on tensile properties}

The strength of SLM TC4 alloys is generally higher than $1,100 \mathrm{MPa}$, but the elongation can only reach $6 \%-8 \%{ }^{[25,26]}$. After HIP, the changes of tensile properties of SLM TC4 are shown in Fig. 8. It can be seen that after HIP, the tensile strength of the samples perpendicular to the building direction decreases from over 1,100 MPa to $862-902 \mathrm{MPa}$, and the elongation increases from less than $8.0 \%$ to $13.2 \%-14.3 \%$, compared with SLM TC4 alloy. The similar variation trend can

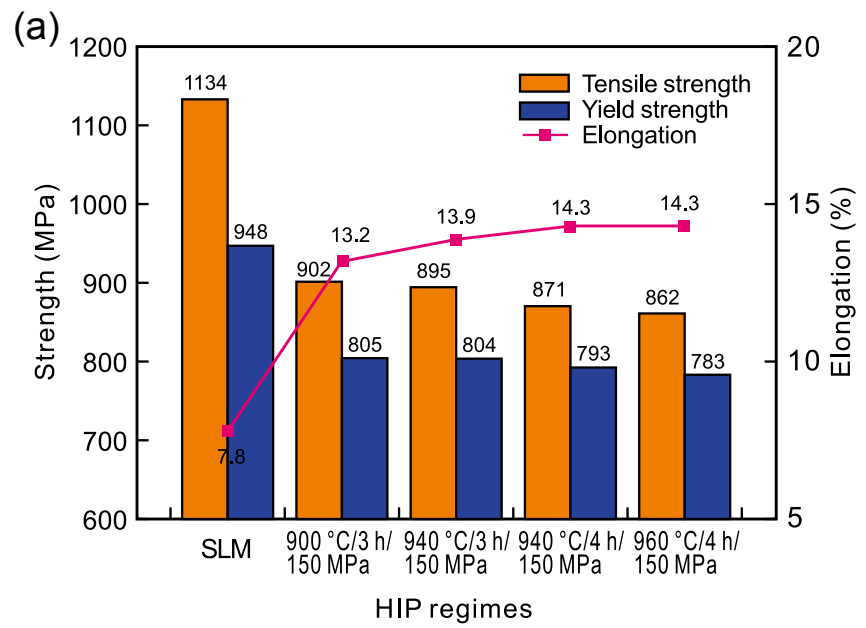

be observed parallel to the building direction after HIP. The tensile strength decreases from 1,107 $\mathrm{MPa}$ to 875-900 MPa, and the elongation increases from $7.3 \%$ to $13.5 \%-14.8 \%$, compared with SLM TC4 alloy, except a slight decrease of elongation under $960{ }^{\circ} \mathrm{C} / 4 \mathrm{~h} / 150 \mathrm{MPa}$. It can also be seen that after HIP, the strength is decreased by about $20 \%$ and the elongation is increased by more than about $70 \%$, and even over $100 \%$, and the strength and the elongation are at the same level in the $X Y$ and $Z$ directions, there is no obvious anisotropy.

Fig. 8: Tensile properties of SLM TC4 alloy with different HIP regimes in different directions: (a) $X Y$ direction; (b) $Z$ direction

The reason for the change of strength and plasticity in SLM TC4 alloy after HIP is that the needle-like martensite $\alpha^{\prime}$ phase changes to $a+\beta$ phase, so the grain refinement strengthening is weakened, and with the dislocation in martensite a' phase moving, the entangled dislocation is recombined, the density of dislocation decreases to release internal stress ${ }^{[27]}$, so the plasticity is improved. Moreover, because the strength of $\beta$ phase is lower than that of $\alpha$ phase, while the plasticity is higher than that of $\alpha$ phase, with the increase of HIP temperature and duration, the ratio of $\beta$ phase increases so that the strength decreases and the plasticity increases. When the HIP regime is $940{ }^{\circ} \mathrm{C} / 3 \mathrm{~h} / 150 \mathrm{MPa}$, the tensile strength and the elongation achieve optimal match, are $890 \mathrm{MPa}$ and $13.9 \%$ in $X Y$ direction, (b)

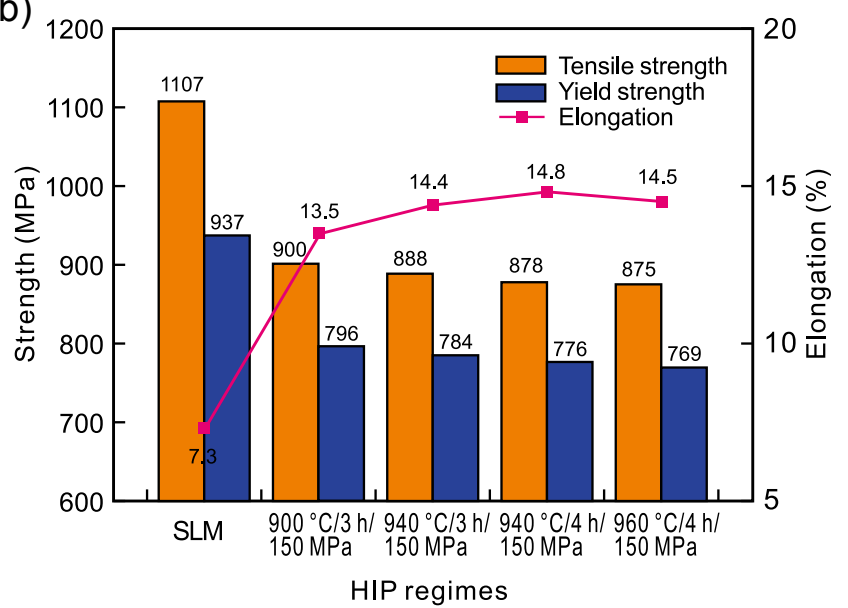

$888 \mathrm{MPa}$ and $14.4 \%$ in $Z$ direction.

The fracture morphology of SLM TC4 alloy after HIP of $940{ }^{\circ} \mathrm{C} / 3 \mathrm{~h} / 150 \mathrm{MPa}$ is shown in Figs. 9 and 10. Figures 9(a) and (b) show the macro fracture morphology of the tensile samples in $X Y$ and $Z$ directions, respectively. The fracture is composed of fiber area and shear lip, and the fracture surface fluctuates greatly. Figures 10(a) and (b) show the micro fracture morphology of the tensile samples in $X Y$ and $Z$ directions, and the circular dimples with different sizes and morphologies can be clearly observed, indicating that the fracture mechanism is ductile fracture, which means good plasticity. The result is consistent with the tensile property testing results shown in Fig. 8.
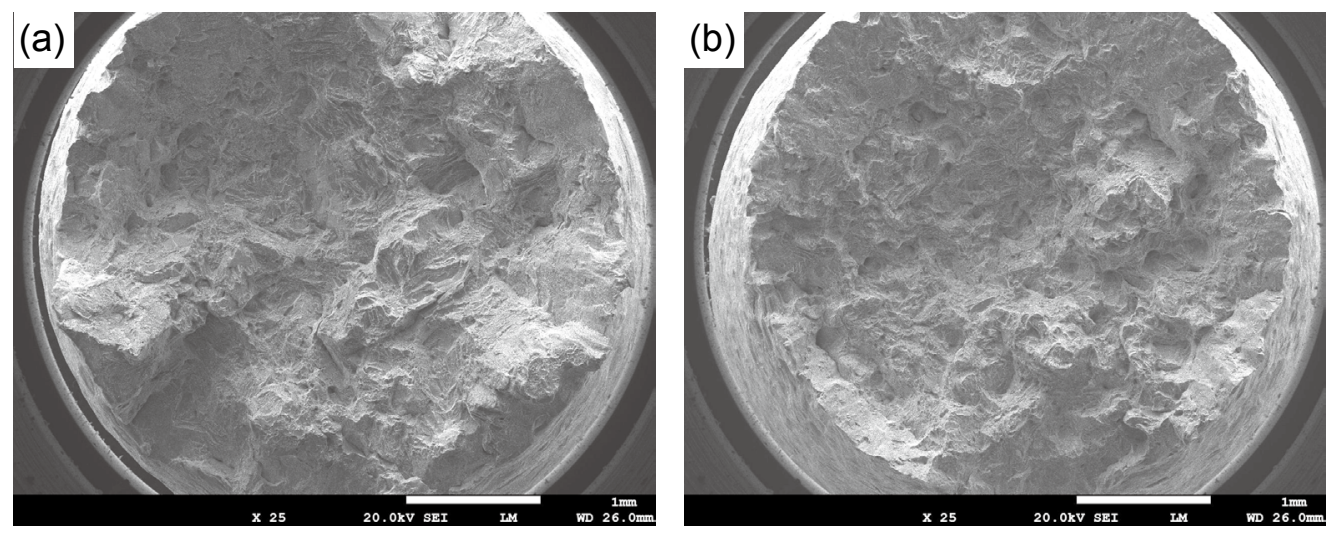

Fig. 9: Low magnification fractograph of SLM TC4 alloy after $940^{\circ} \mathrm{C} / 3 \mathrm{~h} / 150 \mathrm{MPa}$ HIP: (a) XY direction; (b) Z direction 

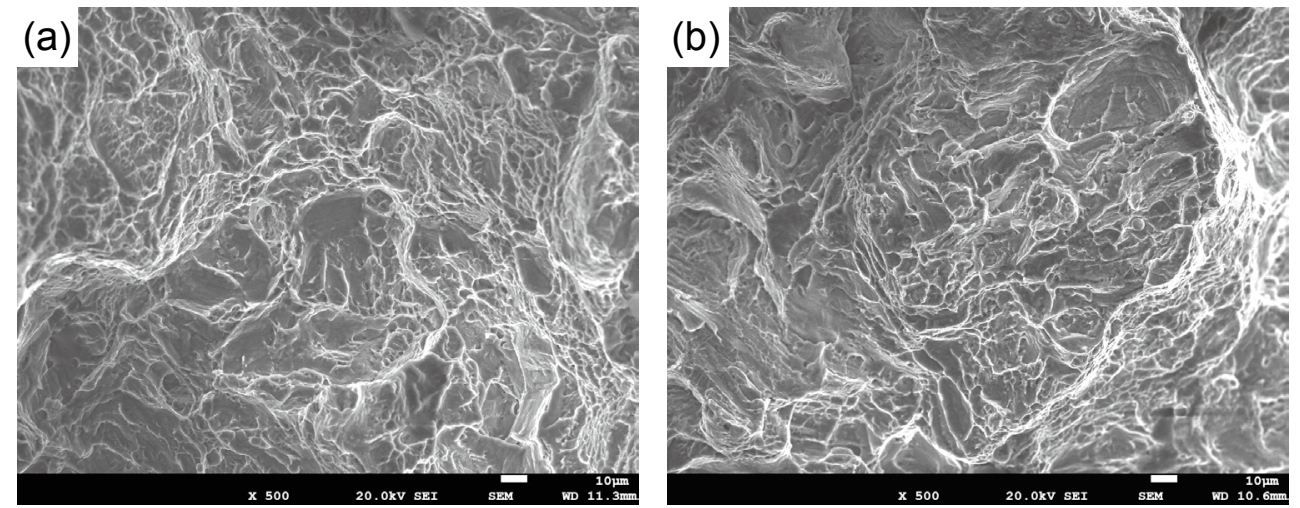

Fig. 10: High magnification fractograph of SLM TC4 alloy after $940{ }^{\circ} \mathrm{C} / 3 \mathrm{~h} / 150 \mathrm{MPa}$ HIP: (a) $X Y$ direction; (b) Z direction

\subsection{Effect of HIP on deformability}

For TC4 alloy parts with thin-walled structure fabricated by selective laser melting, deformation may occur in the process of HIP, which would affect the practical application of the parts. Deformation values are based on the first measurement data (before HIP), and evaluating the deviation of the second measurement data (after HIP). The influence of HIP temperature and duration on the deformation of SLM TC4 alloy thin-walled frames is shown in Fig. 11 and Table 4. It can be seen that after HIP, all four frames have a certain degree of concavity. With the increase of HIP temperature and duration, the maximum concavity gradually increases from $0.154 \mathrm{~mm}$ to $0.293 \mathrm{~mm}$. Compared with the wall thickness $(1.5 \mathrm{~mm})$, the maximum deformation is between $10.3 \%$ and $19.5 \%$.

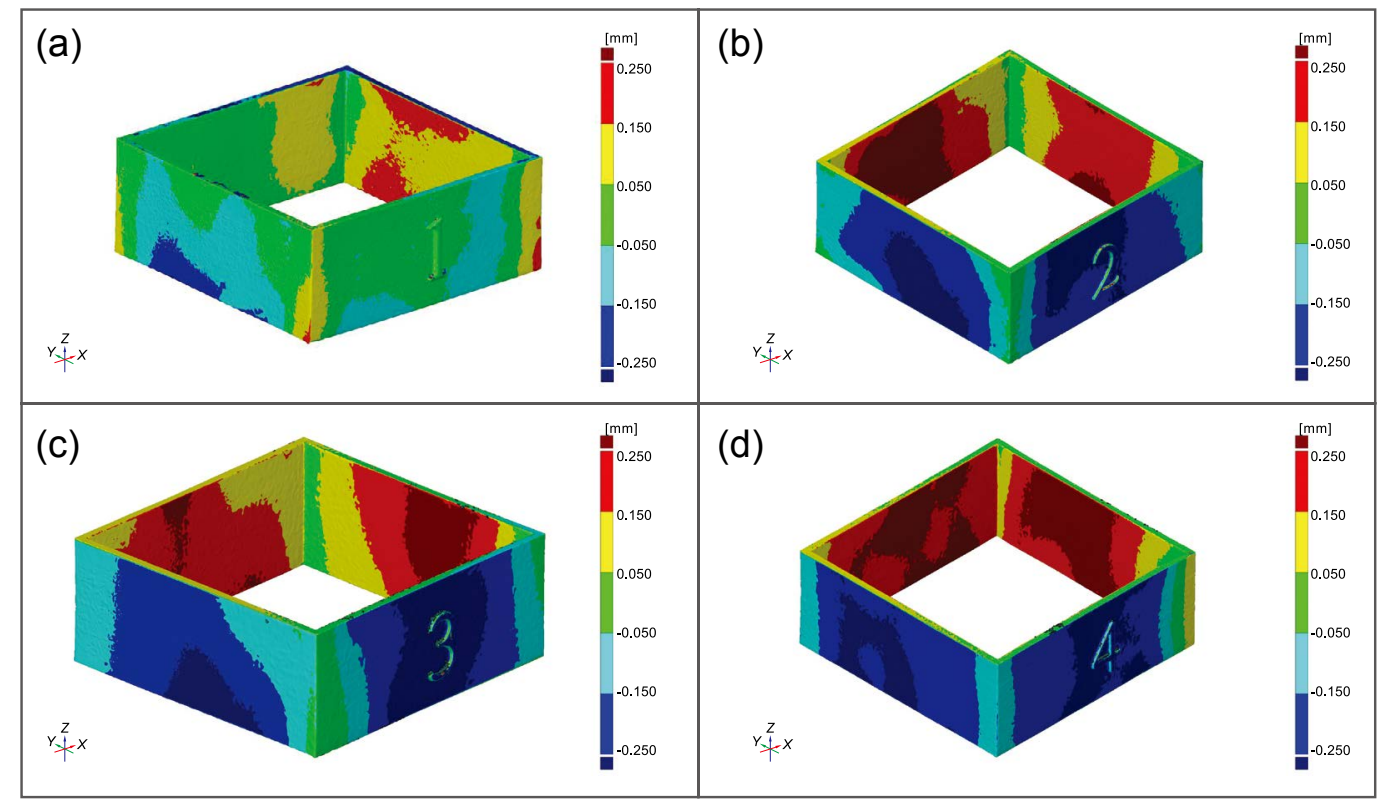

Fig. 11: Deformation diagram of frames under different HIP regimes: (a) $900{ }^{\circ} \mathrm{C} / 3 \mathrm{~h} / 150 \mathrm{MPa}$; (b) $940{ }^{\circ} \mathrm{C} / 3 \mathrm{~h} / 150 \mathrm{MPa}$; (c) $940{ }^{\circ} \mathrm{C} / 4 \mathrm{~h} / 150 \mathrm{MPa}$; (d) $960^{\circ} \mathrm{C} / 4 \mathrm{~h} / 150 \mathrm{MPa}$

Table 4: Deformation analysis of frames under different HIP regimes

\begin{tabular}{|ccc|}
\hline HIP regimes & $\begin{array}{c}\text { Maximum } \\
\text { concavity } \\
(\mathrm{mm})\end{array}$ & $\begin{array}{c}\text { Maximum } \\
\text { deformation } \\
(\%)\end{array}$ \\
\hline $900^{\circ} \mathrm{C} / 3 \mathrm{~h} / 150 \mathrm{MPa}$ & +0.154 & 10.3 \\
$940^{\circ} \mathrm{C} / 3 \mathrm{~h} / 150 \mathrm{MPa}$ & +0.246 & 16.4 \\
$940^{\circ} \mathrm{C} / 4 \mathrm{~h} / 150 \mathrm{MPa}$ & +0.240 & 16.0 \\
$960^{\circ} \mathrm{C} / 4 \mathrm{~h} / 150 \mathrm{MPa}$ & +0.293 & 19.5 \\
\hline
\end{tabular}

It can be found that the HIP temperature and duration have different effects on the deformation of the SLM TC4 alloy thin-walled frames. Maintaining HIP duration at $3 \mathrm{~h}$ and increasing HIP temperature from $900{ }^{\circ} \mathrm{C}$ to $940{ }^{\circ} \mathrm{C}$, the maximum concavity will increase from $0.154 \mathrm{~mm}$ to $0.246 \mathrm{~mm}$. Maintaining HIP duration at $4 \mathrm{~h}$ and increasing HIP temperature from $940{ }^{\circ} \mathrm{C}$ to $960{ }^{\circ} \mathrm{C}$, the maximum concavity will increase from $0.240 \mathrm{~mm}$ to $0.293 \mathrm{~mm}$. However, maintaining HIP temperature at $940{ }^{\circ} \mathrm{C}$ and extending HIP duration from $3 \mathrm{~h}$ to $4 \mathrm{~h}$, the maximum concavity is basically unchanged. From the above discussion, it can be seen that the deformation of the frames increases with the increase of HIP temperature and basically unchanged with the increase of HIP duration. 


\section{Conclusions}

(1) Microstructure of SLM TC4 alloy is characterized by acicular martensite $\alpha^{\prime}$ phase. After hot isostatic pressing, unstable martensite $\alpha^{\prime}$ phase decomposes into $\alpha+\beta$ phase, and with the increase of hot isostatic pressing temperature and duration, $\alpha$ phase with coarse lath is gradually refined and the proportion of $\alpha$ phase decreases.

(2) After hot isostatic pressing, microhardness decreases from $355 \mathrm{HV}$ to around $300 \mathrm{HV}$, tensile strength also decreases from over 1,100 $\mathrm{MPa}$ to $862-902 \mathrm{MPa}$, but the elongation increases from less than $8.0 \%$ to $13.2 \%-14.8 \%$, compared with as-deposited TC4 alloy, and there is no obvious anisotropy. When SLM TC4 alloy is heat treated by $940{ }^{\circ} \mathrm{C} / 3 \mathrm{~h} / 150 \mathrm{MPa}$ hot isostatic pressing, the tensile strength and the elongation in both of $X Y$ and $Z$ directions come to about $890 \mathrm{MPa}$ and around $14.0 \%$, which achieves an optimal match. The fracture mechanism of alloy after $940{ }^{\circ} \mathrm{C} / 3 \mathrm{~h} / 150 \mathrm{MPa}$ HIP is dultile fracture.

(3) Hot isostatic pressing can cause concave deformation of SLM TC4 alloy thin-walled frames (wall thickness: $1.5 \mathrm{~mm}$ ). In this study, the maximum deformation is between $10.3 \%$ and $19.5 \%$. The deformation degree increases with the increase of HIP temperature.

\section{References}

[1] Zhu Z S. Recent research and development of titanium alloys for aviation application in China. Journal of Aeronautical Materials, 2014, 34(4): 44-50. (In Chinese)

[2] Tao P, Li H X, Huang B Y, et al. Tensile behavior of Ti-6Al$4 \mathrm{~V}$ alloy fabricated by selective laser melting: Effects of microstructures and as-built surface quality. China Foundry, 2018, 15(4): 243-252.

[3] Rochus P, Plesseria J Y, Elsen N M V, et al. New applications of rapid prototyping and rapid manufacturing (RP/RM) technologies for space instrumentation. Acta Astronautica, 2007, 61(1): 352-359.

[4] Thijs L, Verhaeghe F, Craeghs T, et al. A study of the microstructural evolution during selective laser melting of Ti6Al-4V. Acta Materialia, 2010, 58: 3303-3312.

[5] Cai Y S, Ji H B, Lei J F, et al. Influence of heat treatment on microstructure and mechanical properties of TC4 titanium alloy fabricated by selective laser melting. Titanium Industry Progress, 2020, 37(1): 14-21. (In Chinese)

[6] Li N, Huang S, Zhang G D, et al. Progress in additive manufacturing on new materials: A review. Journal of Materials Science \& Technology, 2019, 35(2): 242-269.

[7] Lin X, Huang W D. High performance metal additive manufacturing technology applied in aviation field. Materials China, 2015, 34(9): 684-688. (In Chinese)

[8] Yan T Q, Tang P J, Chen B Q, et al. Effect of annealing temperature on microstructure and tensile properties of AISi10Mg alloy fabricated by selective laser melting. Journal of Mechanical Engineering, 2020, 56(8): 37-45. (In Chinese)

[9] Gu D D, Shen Y F. Research status and technical prospect of rapid manufacturing of metallic part by selective laser melting. Aeronautical Manufacturing Technology, 2012(8): 32-37. (In Chinese)
[10] Tian Z J, Gu D D, Shen L D, et al. Application and development of laser additive manufacturing technology in aeronautics and astronautics. Aeronautical Manufacturing Technology, 2015, 11: 38-42. (In Chinese)

[11] Khajavi S H, Holmström J, Partanen J. Additive manufacturing in the spare parts supply chain. Computers in Industry, 2014, 65(1): 50-63.

[12] Kasperovich G, Hausmann J. Improvement of fatigue resistance and ductility of Ti6Al4V processed by selective laser melting. Journal of Materials Processing Technology, 2015, 220: 202214.

[13] Fan Z C, Feng $H$ W. Study on selective laser melting and heat treatment of Ti-6Al-4V alloy. Results in Physics, 2018, 10: 660-664

[14] Liang Z L, Sun Z G, Zhang W S, et al. The effect of heat treatment on microstructure evolution and tensile properties of selective laser melted Ti6Al4V alloy. Journal of Alloys and Compounds, 2018, 782: 1041-1048.

[15] Zhang W X, Tang C L, Chen Z R, et al. Effect of annealing temperature on microstructure and mechanical properties of TC4 titanium alloy formed by selective laser melting. Heat Treatment of Metals, 2019, 44(6): 122-127. (In Chinese)

[16] Xu Q, Zhou J X, Nan H, et al. Effects of hot isostatic pressing temperature on casting shrinkage densification and microstructure of Ti6AI4V alloy. China Foundry, 2017, 14(5): 429-434.

[17] Jiang S, Li H X, Shi Z Q, et al. Effects of hot isostatic pressing on microstructure and tensile properties of direct laser deposited Ti60 alloy. Infrared and Laser Engineering, 2015, 44(1): 107-111. (In Chinese)

[18] Aboulkhair N T, Everitt N M, Ashcroft I, et al. Reducing porosity in AISi10Mg parts processed by selective laser melting. Additive Manufacturing, 2014, 1-4: 77-86.

[19] Zhang F Y, Chen J, Tan H, et al. Research on forming mechanism of defects in laser rapid formed titanium alloy. Rare Metal Materials and Engineering, 2007, 36(2): 211-215. (In Chinese)

[20] Zhang X Y. Titanium alloy and its application. Beijing: Chemical Industry Press, 2005. (In Chinese)

[21] Zong X W, Liu W J, Zhang J, et al. Analysis of mechanical properties of TC4 titanium alloy formed by laser selective melting and casting. Materials Reports, 2020, 34(16): 1608316086. (In Chinese)

[22] Liu S Y, Shin Y C. Additive manufacturing of Ti6Al4V alloy: A review. Materials \& Design, 2019, 164: 107552.

[23] Kobayashi S, Nakagawa S, Nakai K, et al. Phase decomposition in a Ti-13Nb-13Zr alloy during aging at $600{ }^{\circ} \mathrm{C}$. Materials Transactions, 2002, 43(12): 2956-2963.

[24] Dong H B, Zou Z B. A method for improving the superplasticity of metastable beta titanium alloy. China, CN105648375B, National intellectual property administration, 2019. (In Chinese)

[25] Zhu J L, Wang K, Ma G D, et al. Study on TC4 titanium alloy selective laser melting forming mechanical properties. Applied Laser, 2017, 37(6): 793-800. (In Chinese)

[26] Zhang Z C, Liu S F, Xie Y X, et al. Microstructure and mechanical properties of TC4 titanium alloy by laser additive manufacturing. Applied Laser, 2019, 39(3): 400-405. (In Chinese)

[27] Shen $Y$ Z. The formation and development of dislocation theory. Metal World, 1995, 2: 10-11. (In Chinese) 